\title{
Short-stepping gait in severe heart failure
}

\author{
S W Davies, C A Greig, S L Jordan, D W Grieve, D P Lipkin
}

\begin{abstract}
Background-Patients with severe chronic heart failure seem to take shorter steps than healthy controls when walking on a treadmill and when walking freely along a corridor. In healthy individuals the pattern of walking affects the oxygen cost of exercise, and so this observation might be relevant to the limitation of exercise in heart failure.

Method-Length of stride was analysed as stride/stature index in 15 controls, 10 patients with moderate heart failure, 10 patients with severe heart failure, and 10 patients with angina, walking at a constant speed/stature index.

Results-The stride/stature index was 0.64 in the controls in patients with New York Heart Association (NYHA) class II heart failure, and in patients with angina It was 0.49 in patients with NYHA class III heart failure. In the patients with heart failure the stride/stature index correlated with exercise capacity determined as peak oxygen consumption $\mathrm{Vo}_{2} \max (\mathbf{R}=+0.62, \mathrm{p}<0.005)$. When healthy controls walked in time to a metronome adjusted to decrease their stride/stature index to approximately that seen in severe heart failure steadystate oxygen consumption increased by a mean of $15 \%$.

Conclusions-The length of stride is reduced in severe heart failure, and when healthy controls adopt this gait the oxygen cost of walking is increased. A short-stepping gait may contribute to the limitation of exercise capacity in heart failure.
\end{abstract}

(Br Heart J 1992;68:469-72)

Department of Cardiology, Royal Free Hospital and School of Medicine, London

$S$ W Davies

$S$ L Jordan

D P Lipkin

Human Performance

Laboratory, Royal

Free Hospital and

School of Medicine,

London

C A Greig

D W Grieve

Correspondence to:

Dr S W Davies, Cardiac

Department, London Chest

Hospital, Bonner Road,

London E2 9JX.

Accepted for publication

12 March 1992.
A major symptom of patients with chronic heart failure is the limitation of exercise capacity by dyspnoea or by fatigue. ${ }^{12}$ Physiological studies of healthy individuals in the 1950s showed that the pattern of walking influenced the oxygen cost of walking a given distance..$^{3-5}$ Preliminary observations when patients with chronic heart failure were exercise tested suggested that they took shorter and more frequent steps than normal, which in extreme cases amounted to a shuffling gait. These observations were confirmed when the same patients walked freely along a corridor:

It is possible that a short-stepping gait in chronic heart failure influences oxygen consumption and thus exercise capacity. We performed a simple quantitative analysis of gait in patients with chronic heart failure and in controls to determine the prevalence of abnormal gait and its importance. We also studied the effects of artificially altering the pattern of walking in the controls.

\section{Patients and methods \\ PATIENT SELECTION}

Twenty patients (six women and 14 men) with chronic left heart failure who were in New York Heart Association categories II and III were recruited from outpatient clinics. The left ventricular ejection fraction determined by radionuclide gated blood pool scanning was $<45 \%$ in all patients. The aetiology of heart failure in each patient was ischaemic heart disease, and patients had been clinically stable for at least three months before the study. It was our intention to study a group of patients with stable chronic heart failure, without current angina, pulmonary disease, or other symptoms and conditions that might interfere with their ability to walk normally on the treadmill. Therefore the exclusion criteria were: (a) a history of recent angina or abnormal ST segment changes or both during exertion; (b) significant valve disease diagnosed by history, clinical examination, chest $x$ ray, electrocardiogram, and echocardiogram; (c) primary lung disease as judged by history, clinical examination, chest $x$ ray, and standard lung function tests (that is forced expiratory volume in one second, forced vital capacity, or diffusing capacity for lung carbon monoxide, $<70 \%$ of predicted normal values); (d) disturbance of balance or musculoskeletal problems that might affect treadmill exercise.

Ten patients with stable angina in New York Heart Association (NYHA) categories II and III were recruited from outpatient clinics. None had any evidence of left ventricular failure, and each had $<1 \mathrm{~mm}$ ST segment depression at peak exertion.

Fifteen age matched controls were recruited from among members of the laboratory staff and healthy elderly subjects participating in a general practice survey of the elderly in the community. None had any evidence of cardiac or respiratory disease as judged by history, physical examination, and resting 12 lead electrocardiogram. Gait indices in healthy people over a range of different ages had already been established in this laboratory by Grieve $^{6}$ and were used for reference.

The project was approved by the local ethics committee, and all subjects gave written consent. Each subject was required to attend the hospital on at least three occasions for exercise 
testing and associated tests, and those who agreed to enter the study were thus self-selected for a high level of cooperation. Subjects were unaware of the purpose of the study.

FREE CORRIDOR WALKING

Subjects walked freely along a 250 m corridor, with the instruction to walk at their "usual comfortable pace". No data were recorded until subjects reached the $50 \mathrm{~m}$ mark, to allow them to settle into a rhythm and pace of walking; the time taken and the number of strides taken over the final $200 \mathrm{~m}$ were recorded.

\section{TREADMILL EXERCISE TESTING}

Subjects were practised in treadmill exercise, and performed maximal symptom-limited exercise according to the modified Bruce protocol. Collection of mixed expired gases allowed the determination of ventilation by argon dilution and of oxygen consumption. ${ }^{7}$ Exercise capacity was taken as peak oxygen consumption $\left(\mathrm{Vo}_{2} \mathrm{max}\right)$. The reproducibility of $\mathrm{Vo}_{2}$ max determined on repeat testing was within $10 \%$ (mean difference $-0.19 \mathrm{ml} . \mathrm{kg}^{-1}$. $\mathrm{min}^{-1}$, standard deviation of the differences $\pm 1 \cdot 18 \mathrm{ml} \cdot \mathrm{kg}^{-1} \cdot \mathrm{min}^{-1}$ ).

\section{ANALYSIS OF GAIT}

We checked the speed of the treadmill belt while each subject was exercising by recording the time taken for marks on the belt of known length to pass the observer. Because stride length depends on speed and on height, ${ }^{6}$ each subject was exercised at a speed adjusted for his or her height. Height was measured with a Harpenden stadiometer and subjects walked at a treadmill speed calculated to give a speed/ stature ratio of $0.5 \mathrm{~s}^{-1}$ (approximately $2 \mathrm{mph}$ (3 $\mathrm{km} / \mathrm{h}$ ) in most subjects). When a steady state was attained for oxygen consumption and number of strides per unit time, we recorded the number of strides per minute and from the known velocity of the treadmill belt we obtained the stride length. The stride/stature index was then calculated as stride length divided by height. ${ }^{6}$ The reproducibility of stride/stature analysis on repeat testing was within $10 \%$ (mean difference +0.02 , standard deviation of the differences \pm 0.04 ).

\section{WALKING TO A METRONOME}

On a separate occasion steady state oxygen consumption was determined for 12 controls walking under each of three different conditions. First, with the treadmill set to a speed/ stature index of $0.5 \mathrm{~s}^{-1}$ subjects walked with their normal gait. Second, subjects were then asked to walk in time to a metronome set to a rate calculated to quicken their step and to give a stride/stature ratio similar to that seen in patients with heart failure (approximately 0.5). Third, the metronome was reset to their previously recorded natural stepping rate.

\section{STATISTICAL ANALYSIS}

Because normal distribution of the values can not be assumed we used non-parametric statistics throughout. Values are given as median and range, comparisons between groups were made by the Mann-Whitney U-Statistic, and paired comparisons were made by the Wilcoxon test. Correlations were explored by means of the Spearman rank correlation coefficient. The reproducibility of repeat testing was assessed by the algebraic mean difference and the standard deviation of the differences.

\section{Results}

\section{PATIENT CHARACTERISTICS}

Patients with chronic heart failure were aged 47-78 years (median 65) and the left ventricular ejection fraction was $5-40 \%$ (median $23 \%$ ). Peak oxygen consumption $\mathrm{Vo}_{2}$ max was 11.9$23.4 \mathrm{ml} \cdot \mathrm{kg}^{-1} \cdot \mathrm{min}^{-1}$ (median $14.8 \mathrm{ml} \cdot \mathrm{kg}^{-1} \cdot \mathrm{min}^{-1}$ ). The controls were aged 50-75 years (median 66). Peak oxygen consumption $\mathrm{Vo}_{2}$ max was 33.9-55.7 ml. $\mathrm{kg}^{-1} \cdot \mathrm{min}^{-1}$ (median $40.8 \mathrm{ml} . \mathrm{kg}^{-1}$. min $^{-1}$. Patients with angina were aged 45-71 years (median 63). Peak oxygen consumption was not determined in this group.

\section{GAIT ANALYSIS: FREE CORRIDOR WALKING}

The free walking speed/stature index was similar in controls $\left(0.57-0.84\right.$, median $\left.0.70 \mathrm{~s}^{-1}\right)$ and in angina $\left(0.59-0.82\right.$, median $\left.0.70 \mathrm{~s}^{-1}\right)$. The speed/stature index for free walking was reduced in patients with NYHA class II heart failure (0.50-0.77, median $0.62 \mathrm{~s}^{-1}, \mathrm{p}<0.005$ compared with controls) and in class III heart failure $\left(0.42-0.60\right.$, median $0.50 \mathrm{~s}^{-1}, \mathrm{p}<0.001$ compared with controls). The stride/stature index was similar in controls $(0.71-0.96$, median 0.82$)$ and in patients with angina (0.64 0.98 , median 0.81 ) but was reduced in patients with NYHA class II heart failure (0.61-0.89, median $0.74, \mathrm{p}<0.05$ compared with controls) and in patients with class III heart failure (0.33-0.56, median $0.48, p<0.001$ compared with controls).

Figure 1 shows the stride/stature index plotted against the speed/stature index. Values for patients with class III heart failure lie below the normal range previously defined in this laboratory. ${ }^{7}$

GAIT ANALYSIS: STANDARDISED TREADMILL SPEED At a constant speed/stature index of $0.5 \mathrm{~s}^{-1}$ the stride/stature index was not significantly different in controls $(0.49-0.78$, median 0.63$)$,

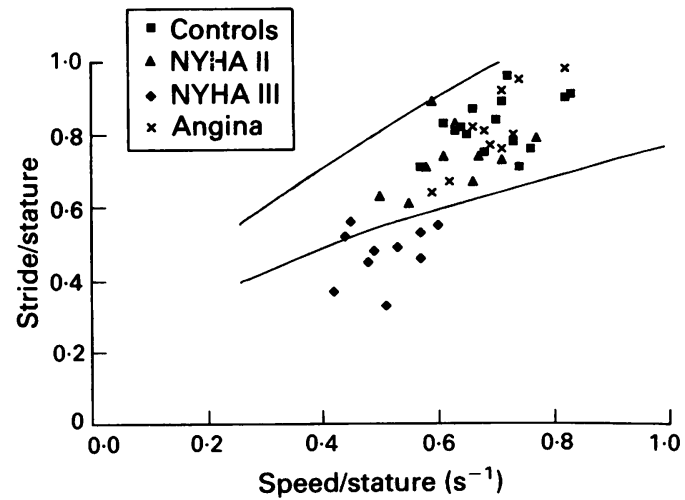

Figure 1 Normalised length of stride (stride/stature) and normalised speed (speed/stature) during free corridor walking. The two lines define the normal range, taken from Grieve 1989. ${ }^{6}$ 
in NYHA class II heart failure (0.57-0.81, median 0.65 ), and in patients with angina $(0.55-0.71$, median 0.64$)$. The stride/stature index was reduced in NYHA class III heart failure $(0.33-0.60$, median 0.49$)(p<0.001$ compared with each of the other groups) (fig 2).

Within the group of patients with heart failure (class II and class III) the stride/stature index correlated with $\mathrm{Vo}_{2} \max , \mathrm{R}=+0.62$, p $<0.005$ (fig 3).

\section{ARTIFICIALLY SHORTENED STRIDE IN HEALTHY INDIVIDUALS}

When 12 controls exercised at a constant speed/ stature of $0.5 \mathrm{~s}^{-1}$ and then walked in time to metronome adjusted to give a stride length/ stature index of approximately 0.5 , the steady state oxygen consumption rose from $10 \cdot 1-14 \cdot 0$ (median 11.7) $\mathrm{ml} \cdot \mathrm{kg}^{-1} \cdot \mathrm{min}^{-1}$ to $10 \cdot 1-14 \cdot 2$ (median 13.0) $\mathrm{ml} \cdot \mathrm{kg}^{-1} \cdot \mathrm{min}^{-1}, \mathrm{p}<0.005$ (fig 4). When subjects then walked in time to the metronome reset to their original stepping rate, the steady state oxygen consumption decreased to $10.5-13.8$ (median 11.6) $\mathrm{ml} \cdot \mathrm{kg}^{-1} \cdot \mathrm{min}^{-1}$. The mean increase in steady state oxygen consumption at the shortened stride/stature index was $15 \%$.

\section{Discussion}

Limitation of exercise capacity by dyspnoea and by fatigue is a common symptom of patients with chronic heart failure ${ }^{12}$ but the pathophysiological basis is unclear. ${ }^{89}$ It has previously been noted that during treadmill

Figure 2 Standardised length of stride (stride) stature) at a standardised speed (speed/stature $\left.0 \cdot 5^{-1} \mathrm{~s}\right)$.

Figure 3 Relation between stride/stature and exercise capacity $\left(\mathrm{O}_{2}\right.$ max) in heart failure.
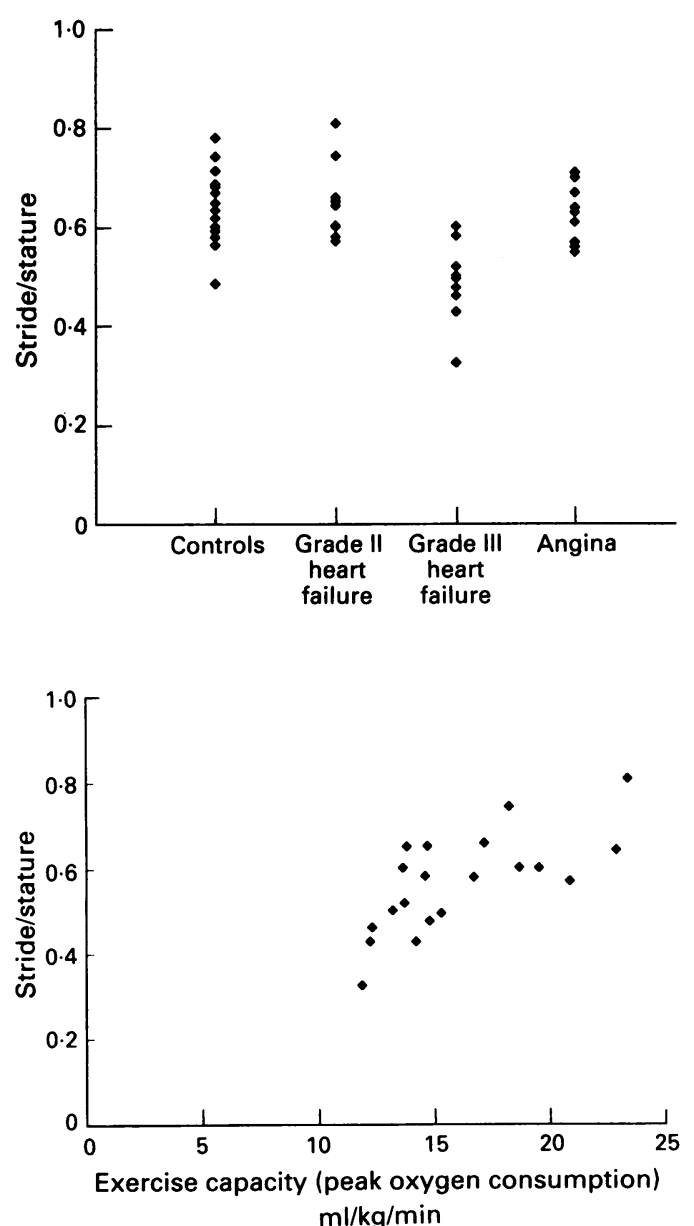

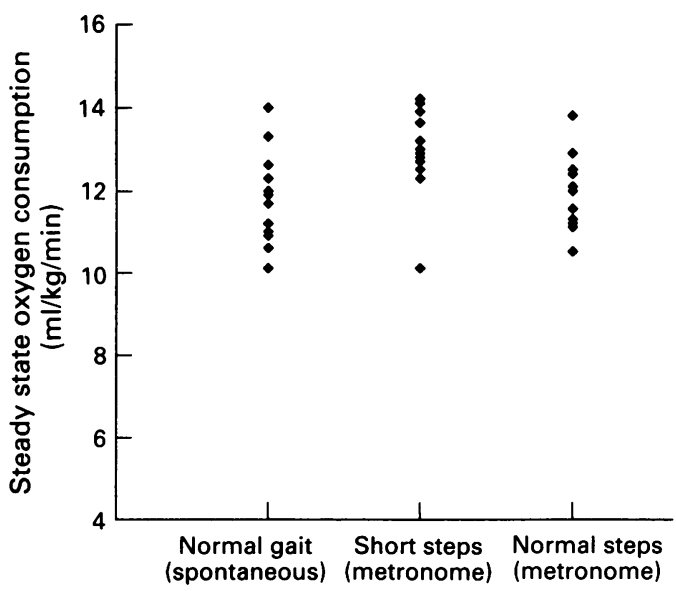

Figure 4 Steady state oxygen consumption in controls walking normally (unconstrained), constrained to a short stride/stature, and constrained to their normal stride/ stature.

exercise, patients with chronic heart failure take shorter and more frequent steps than controls. If this gait were inefficient it might contribute to the limitation of exercise.

Analysis of the walking pattern in healthy people has defined ranges for simple indices of gait such as the stride length. ${ }^{61011}$ Stride length is usually standardised to the subject's height to give a "stride/stature index", and walking speed is similarly expressed as a "speed/stature index". ${ }^{11}$ The stride/stature index depends on the age of the subject and on walking speed. ${ }^{6112}$ These relations are the same for women and for men when standardised for height. ${ }^{6}$

We measured the short-stepping gait of patients with severe chronic heart failure. Possible reasons for this gait may lie in the abnormalities of blood supply, histology, biochemistry, and strength of skeletal muscle in heart failure. ${ }^{13-16}$ First, it is possible that the muscles are less able to sustain the contraction necessary for a long stride: walking speed and the number of steps taken correlate with calf muscle strength in normal elderly subjects. ${ }^{17} 18$ Second, frequent short steps may minimise discomfort in the muscles: important reflexes may arise from the sensory endings in skeletal muscle, ${ }^{19}$ and leg discomfort is associated with reduced walking speed in the elderly. ${ }^{17} 18$ Third, a short-stepping gait might reflect anxiety in a person exercising on the treadmill. However, all subjects in the present study were well practised in treadmill exercise and were not overtly anxious; furthermore, the shortstepping gait was as apparent during free corridor walking as during treadmill exercise.

Theoretical considerations suggest that there should be an optimal speed and pattern of walking for which the mechanical power output is a minimum. ${ }^{20}$ Actual observations have shown that oxygen consumption during walking varies with the speed and pattern of gait and that there is an optimal pattern of walking for which oxygen consumption is at a minimum (fig 5). ${ }^{51021}$

Attempts to modify the stride length of patients with severe heart failure were unsuccessful because they were unable consistently to lengthen their stride to walk in time with a 
Figure 5 Relation between speed of walking and oxygen consumption in a healthy individual (from Ralston $1958^{5}$ ).

(Reproduced with permission of SpringerVerlag.)

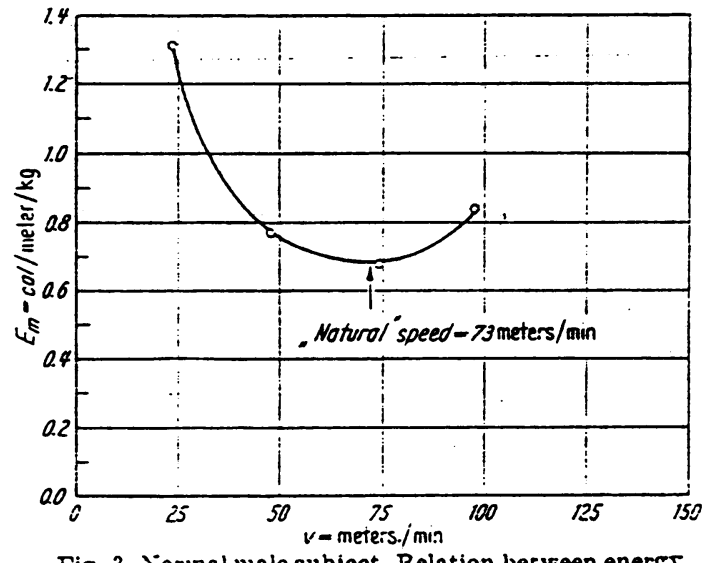

Fig. 3. Norinal male subject. Relation becween eners arpenditure in cal/meter/ke and sneed. Arrot "it:".s thic "natural" "alkinar speed of subject

preset metronome. However, we were able to measure the effects of shortening the relative stride of controls to values seen in patients with heart failure and this manoeuvre increased steady-state oxygen consumption by a mean of $15 \%$. This change might simply have been the result of being constrained to walk in time to the metronome because precisely timed limb movements often involve the simultaneous activation of agonist and antagonist muscle groups. In the present study the change is attributable to the shortened stride rather than to the metronome because when the metronome was set back to the previously noted spontaneous stepping rate, steady state oxygen consumption returned to baseline values.

These observations raise the possibility that the short stepping gait of severe chronic heart failure is inefficient in terms of oxygen consumption. If this were so it might increase oxygen consumption during exercise at a given workload and contribute to the limitation of exercise capacity. If $\mathrm{Vo}_{2}$ max is severely limited, then even a small increase in the oxygen cost of a task may make the difference between being able to complete a task. This might then bear on the patient's ability to perform everyday activities, and thus on the quality of life.

We should however be cautious about inferring that the short-stepping gait in heart failure is suboptimal. In general, in adapting to disease the cardiorespiratory control systems adopt the most efficient pattern; for example, changes in ventilatory pattern in pulmonary and in cardiac

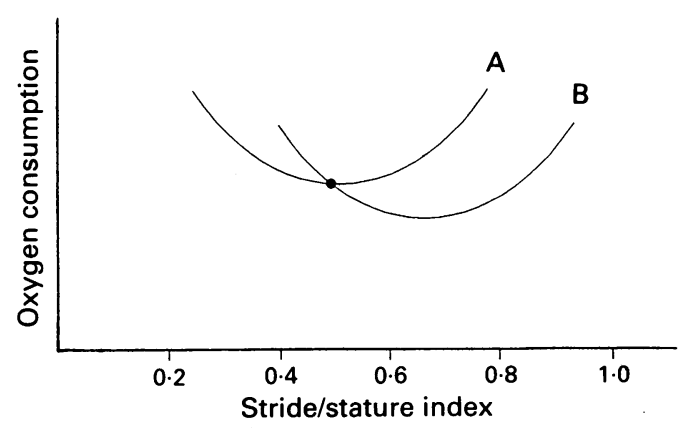

Figure 6 Possible relations between stride/stature and oxygen consumption in heart failure. Line $A$ represents the theoretical possibility that the observed gait (indicated by the heavy dot) is the most efficient. Line B represents the possibility that the observed gait is suboptimal in terms of efficiency, requiring a higher oxygen consumption than a gait with a longer (normal) stride. disease. $^{22-24}$ It is therefore possible that the short-stepping gait represents the most efficient pattern of walking for patients with heart failure, represented by hypothetical line A in fig 6. Alternatively the short-stepping gait may be suboptimal in terms of oxygen consumption (hypothetical line $B$ in fig 6) but represent the price paid for some other (unrecognised) advantage of this pattern of walking. It is unfortunate that we were unable to alter the gait of patients with severe heart failure.

In summary, we found a short-stepping gait in chronic heart failure, that correlated with reduced exercise capacity $\left(\mathrm{Vo}_{2} \max \right)$. This may lead to an increased oxygen consumption at a given workload, and it is thus possible that an inefficient gait contributes to the limitation of exercise capacity in severe heart failure.

During this study SD was a junior research fellow of the British Heart Foundation, and gratefully acknowledges their support.

1 Braunwald E. Clinical manifestations of heart failure. Chapter 16 in: Braunwald E, ed. Heart disease, 3rd edition. Philadelphia, W B Saunders, 1988: 471-84.

2 Sutton GC. In: Julian DG, Camm AJ, Fox KM, Hall RJC Pool-Wilson PA, eds. Diseases of the heart. London: Bailliere Tindall, 1989:92-5.

3 Daniels F, Vanderbie JH, Winsmann FR. Energy cost of treadmill walking compared to road walking. Report No 220, Environmental Protection Division, Natick QM 220, Environmental Protection Division, Natick QM
Research and Development Laboratory; Laurence, Massachussetts 1953.

4 Booyens J, Keatinge, WR. The expenditure of energy by men and women walking. $J$ Physiol 1957;138:165-71

5 Ralston $\mathrm{HJ}$. Energy-speed relation and optimal speed during level walking. Int $Z$ Angew Physiol 1958;17:277-83.

6 Grieve DW. Timing and placement of the feet. Seminars Orthopaed 1989;4:130-4.

7 Davies N, Dennison DM. Measurement of metabolic gas exchange and minute ventilation by mass spectrometry alone. Respir Physiol 1979;36:261-7.

8 Lipkin DP, Poole-Wilson PA. Symptoms in chronic heart failure $B r$ Med $J$ 1986;292:653-5.

9 Poole-Wilson PA, Buller NP. Causes of symptoms in chronic congestive heart failure and implications for treatment. Am J Cardiol 1988;62(suppl):31-4.

10 Dean CA. An analysis of the energy expenditures in level and grade walking. Ergonomics 1965;8:31-48.

11 Grieve DW, Gear RJ. The relationships between length of stride, step frequency, time of swing and speed of walking for children and adults. Ergonomics 1966;5:379-99.

12 Cavanagh PR. Patterns of muscular action and movement associated with the range of speeds used in normal human locomotion. $\mathrm{PhD}$ thesis, University of London 1972.

13 Wiener DH, Fink LI, Maris J, Jones RA, Chance B, Wilson JR. Abnormal skeletal muscle bioenergetics during exercise in patients with heart failure; role of reduced muscle cise in patients with heart failure; role of
blood flow. Circulation 1986;73:1127-36.

14 Mancini DM, Coyle E, Coggan A, Beltz J Ferraro N, Montain S, Wilson JR. Contribution of intrinsic skeletal muscle changes to ${ }^{31} \mathrm{P}$ NMR skeletal muscle metabolic abnormalities in patients with chronic heart failure. Cir culation 1989;80:1338-46.

15 Davies SW, Lipkin DP. Exercise physiology and changes in the periphery. Current Opinion in Cardiology, 1991;6:352-7.

16 Buller N, Poole-Wilson PA. Direct measurement of skeletal muscle fatigue in patients with chronic heart failure. $\mathrm{Br}$ Heart J 1991;65:20-4.

17 Bassey EJ, Bendall MJ, Pearson M. Muscle strength in the triceps surae and objectively measured customary walking activity in men and women over 65 years of age. Clin $S c i$ activity in men

18 Bendall MJ, Bassey EJ, Pearson MB. Factors affecting walking speed of elderly people. Age Ageing 1989;18: 327-32.

19 Rowell LB, Sheriff DD. Are muscle chemoreflexes functionally important? News Physiol Sci 1988;3:250-3.

20 Maynard-Smith J. Mathematical ideas in biology; Cambridge University Press, Cambridge, 1968:14-16.

21 Hogberg $P$. How do stride length and stride frequency influence the energy-output during running? Arbeitsphysiologie 1952;14:437-41.

22 Otis AB, Fenn WO, Rahn $\mathrm{H}$. Mechanics of breathing in man. J Appl Physiol 1950;2:592-607.

23 Haywood GW, Knott JMS. The effect of exercise on lung distensibility and respiratory work in mitral stenosis. $B r$ distensibility and respira.

24 Grodins FS, Yamashiro SM. What is the pattern of breathing regulated for? In: Von Euler C, Lagercrantz $\mathrm{H}$, eds. Oxford: Pergamon, 1979:169-75. 